\title{
Design and fabrication of a Nano-based neutron shield for fast neutrons from medical linear accelerators in radiation therapy
}

\author{
Younes Afkham ${ }^{1}$, Asghar Mesbahi ${ }^{2}$, Abdolali Alemi ${ }^{3}$, Farhad Zolfagharpour ${ }^{4}$ and Nasrollah Jabbari ${ }^{5^{*}}$ (D)
}

\begin{abstract}
Background: Photo-neutrons are produced at the head of the medical linear accelerators (linac) by the interaction of high-energy photons, and patients receive a whole-body-absorbed dose from these neutrons. The current study aimed to find an efficient shielding material for fast neutrons.
\end{abstract}

Methods: Nanoparticles (NPs) of $\mathrm{Fe}_{3} \mathrm{O}_{4}$ and $\mathrm{B}_{4} \mathrm{C}$ were applied in a matrix of silicone resin to design a proper shield against fast neutrons produced by the $18 \mathrm{MeV}$ photon beam of a Varian $2100 \mathrm{C} / \mathrm{D}$ linac. Neutron macroscopic cross-sections for three types of samples were calculated by the Monte Carlo (MC) method and experimentally measured for neutrons of an Am-Be source. The designed shields in different concentrations were tested by MCNPX MC code, and the proper concentration was chosen for the experimental test. A shield was designed with two layers, including nano-iron oxide and a layer of nano-boron carbide for eliminating fast neutrons.

Results: MC simulation results with uncertainty less than 1\% showed that for discrete energies and 50\% nanomaterial concentration, the macroscopic cross-sections for iron oxide and boron carbide at the energy of 1 $\mathrm{MeV}$ were $0.36 \mathrm{~cm}^{-1}$ and $0.32 \mathrm{~cm}^{-1}$, respectively. For $30 \%$ nanomaterial concentration, the calculated macroscopic cross-sections for iron oxide and boron carbide shields for Am-Be spectrum equaled $0.12 \mathrm{~cm}^{-1}$ and $0.15 \mathrm{~cm}^{-1}$, respectively, while they are $0.15 \mathrm{~cm}^{-1}$ and $0.18 \mathrm{~cm}^{-1}$ for the linac spectrum. In the experiment with the Am-Be spectrum, the macroscopic cross-sections for $30 \%$ nanomaterial concentration were $0.17 \pm 0.01 \mathrm{~cm}^{-1}$ for iron oxide and $0.21 \pm 0.02 \mathrm{~cm}^{-1}$ for boron carbide. The measured transmission factors for 30\% nanomaterial concentration with the Am-Be spectrum were $0.71 \pm 0.01,0.66 \pm 0.02$, and $0.62 \pm 0.01$ for the iron oxide, boron carbide, and double-layer shields, respectively. In addition, these values were $0.74,0.69$, and 0.67 , respectively, for $M C$ simulation for the linac spectrum at the same concentration and thickness of $2 \mathrm{~cm}$.

Conclusion: Results achieved from MC simulation and experimental tests were in a satisfactory agreement. The difference between $M C$ and measurements was in the range of 10\%. Our results demonstrated that the designed double-layer shield has a superior macroscopic cross-section compared with two single-layer nanoshields and more efficiently eliminates fast photo-neutrons.

Keywords: Nanoparticle, $\mathrm{Fe}_{3} \mathrm{O}_{4}, \mathrm{~B}_{4} \mathrm{C}$, Silicone resin, Nanoshield, Neutron, Shielding, Photo-neutron

\footnotetext{
* Correspondence: njabbarimp@gmail.com

${ }^{5}$ Solid Tumor Research Center, Cellular and Molecular Medicine Institute, Urmia University of Medical Sciences, Urmia, Iran

Full list of author information is available at the end of the article
}

(c) The Author(s). 2020 Open Access This article is licensed under a Creative Commons Attribution 4.0 International License, which permits use, sharing, adaptation, distribution and reproduction in any medium or format, as long as you give appropriate credit to the original author(s) and the source, provide a link to the Creative Commons licence, and indicate if changes were made. The images or other third party material in this article are included in the article's Creative Commons licence, unless indicated otherwise in a credit line to the material. If material is not included in the article's Creative Commons licence and your intended use is not permitted by statutory regulation or exceeds the permitted use, you will need to obtain permission directly from the copyright holder. To view a copy of this licence, visit http://creativecommons.org/licenses/by/4.0/. The Creative Commons Public Domain Dedication waiver (http://creativecommons.org/publicdomain/zero/1.0/) applies to the data made available in this article, unless otherwise stated in a credit line to the data. 


\section{Introduction}

Application of external photon beam radiation therapy with the energy greater than $10 \mathrm{MeV}$ produces unwanted photo-neutrons. These neutrons are produced at the head of the medical linear accelerator (linac) through photon interaction with the nuclei of materials with a high atomic number, found in target, primary, and secondary collimators, flattening filter, etc. [1-3]. Consequently, neutron-absorbing materials have been utilized as barriers in maze and treatment room walls, examples of which include concrete and borated polyethylene in the doors of treatment rooms [4-6]. These barriers must be of sufficient thickness to protect radiation workers in radiation therapy installations [7].

In radiotherapy with megavoltage photon beams the risk of secondary primary cancer increases in out-offield organs due to the stray dose caused by the photons scattered from the treatment head, photons leakage through treatment head components, photo-neutrons produced in the treatment head, and photons scattered within the patient [8-11]. The fractional radiation dose contribution of photo-neutrons relative to scattered photons in out-of-field is about 28\% [12].

Photo-neutrons are particles with higher penetration and relative biological effectiveness (RBE) with respect to charged particles and sparsely ionizing radiations respectively $[13,14]$. As a consequence, the radiation quality factor (QF) for photo-neutrons produced in radiation therapy with the energy range of $0.1-2 \mathrm{MeV}$ is $20[13,14]$. Therefore, in regard to the cancer induction, even small doses of photo-neutrons outside of the target volume can be important $[8,15]$.

Several studies have been conducted on the application of novel shielding materials for neutrons [16-18], most of which aimed to shield thermal neutrons to prevent these neutrons from emitting out of treatment rooms [19-21]. In recent studies, new composites have been applied for neutron shielding, and various particle sizes have been utilized as filters in different base materials for thermal neutron shielding, including micro- and nano-sized boron carbide and dense polyethylene $[5,7,22]$. Compared with microsized particles, nano-sized particles can be more homogeneously spread in the shield matrix with less aggregation. Hence, nanocomposite shields present higher shielding capabilities in radiation protection against both thermal and fast neutrons [21-23]. In addition, shielding materials with nanoparticles (NPs) shows high levels of tensile and flexural strengths [21-23]. The size and concentration of NPs are two factors influencing the fabrication of neutron shields [21-23]. The Monte Carlo (MC) simulation method plays a vital role in understanding the effect of parameters such as particle size, concentration, and radiation energy. Also, in designing a new shield, it provides the possibility of selecting various materials in different combinations.
Concrete and boron carbide-based products are commonly employed as shields for neutrons in radiation therapy due to their properties such as low price and high absorbing cross-sections for shielding neutrons [1, 22, 24]. Photo-neutrons are produced at the head of medical linac by the interaction of high-energy photons $(E>10 \mathrm{MeV})$, and patients receive a whole-body-absorbed dose from these neutrons $[2,3,14]$. To the best of our knowledge, no study has been dedicated to shielding materials with flexibility and low weight to prevent these neutrons from reaching patients.

According to several studies, composites containing nano-boron such as boron carbide, lead borate, and bismuth borate have been used for thermal neutron attenuation due to the high cross-section of boron as a neutron absorber. Iron oxide has shown high efficiency in attenuating and eliminating fast neutrons $[17,25,26]$. In this study, a double-layer shield consisting of nano-iron oxide and nano-boron carbide was designed to attenuate photoneutrons with a broad energy range, which is the novelty of the present study.

Reviewing the published literature revealed the unavailability of a shield for protecting patients from fast generated neutrons in linacs. Therefore, the present investigation aimed to find an efficient shielding material for fast neutrons by applying nano-boron carbide and nano-iron oxide in a base of silicone resin. The goal of this research was to evaluate and compare the attenuating characteristics of both nanomaterials (boron carbide and iron oxide) for the range of fast neutron energies produced in radiation therapy and then design and fabricate a shield with a reasonable yield of neutron attenuation.

\section{Methods}

\section{Shielding parameters}

\section{Macroscopic cross-section}

This parameter, denoted by $\Sigma$, describes the probability of interaction of a neutron with a target material with units of $\mathrm{cm}^{-1}$

$$
\mathrm{I}_{\mathrm{x}}=\mathrm{I}_{0} \mathrm{e}^{-\Sigma \mathrm{x}} \text { or } \ln \left(\frac{\mathrm{Ix}}{10}\right)=-\Sigma \mathrm{x} \text { or }-\Sigma=1 / \mathrm{x} \cdot \ln \left(\mathrm{I}_{\mathrm{x}} / \mathrm{I}_{0}\right)
$$

where $\mathrm{I}_{0}$ and I show the intensities of initial and attenuated neutrons, respectively, and $\mathrm{X}$ denotes the thickness of the absorber. $\mathrm{Ix} / \mathrm{I}_{0}$ is called the transmission factor [27].

\section{Neutron characterization}

We evaluated the fluence and spectra of neutrons with energy ranging from $0.4 \mathrm{eV}$ to $15 \mathrm{MeV}$, which is more than the energy of thermal neutrons $(0.025 \mathrm{eV})$ [6]. For this reason, in the investigated spectra, all neutron energy ranges were used and considered as fast neutrons. 


\section{Monte Carlo simulation}

In this study, simulations were performed using MCNPX MC code version 2.6.0 [28]. A narrow-beam geometry was modeled that included a point source (emitting neutrons vertically to the entrance surface of a detector), a collimator made of cadmium surrounding the point source, the designed nano-material shield, a sphere volume with diameter of $1 \mathrm{~cm}$ defined as a detector, and a collimator made of cadmium surrounding the detector (Fig. 1a). A shield was simulated between the source and the detector (Fig. 1a). Tally F4 (F4:n) was utilized for detecting the number of neutrons reaching the detector in terms of neutron $/ \mathrm{cm}^{2}$. In MCNP MC code, the F4:n tally calculates the average neutron fluence per simulated source-neutron within the cell detector.

Initially, the fluence of neutrons in the detector cell $\left(\mathrm{I}_{0}\right)$ was calculated for the narrow beam geometry without the nanoshields between the source and detector. Next, nanoshields with different thicknesses were placed between the source and detector cell, and the fluences of neutrons were calculated in the detector cell $\left(I_{x}\right)$ for each of them. Afterward, the transmission factors were determined by dividing $I_{x}$ to $I_{0}$. Finally, the macroscopic cross-section of each nanoshield in different concentrations and thicknesses was calculated by Eq. 1 .

Three types of neutron energies were used in our simulations. First, monoenergetic neutrons including 1-10 $\mathrm{MeV}$ with steps of $1 \mathrm{MeV}$ were defined in our calculations. The second neutron source was the neutron spectra of an Am-Be source (Fig. 2a) obtained from previous studies $[29,30]$. The third neutron source was the $18 \mathrm{MV}$ photon beam of Varian $2100 \mathrm{C} / \mathrm{D}$ medical linear accelerator (Fig. 2a) obtained from other studies [3, 31, 32]. Finally, to compare our $\mathrm{MC}$ results with experimental measurements and to test the designed and fabricated nanoshields, the experimental measurements were performed with a neutron source of an Am-Be in the laboratory (Fig. 2b). Because of the lack of access to energy spectrum raw data from the Am-Be source in the laboratory, this spectrum was not used in the simulations.

\section{Simulations validation with lead}

To validate this model, photon mass attenuation coefficients were tested for lead shields for different energies. The MC simulations were tested versus published reference data (33).

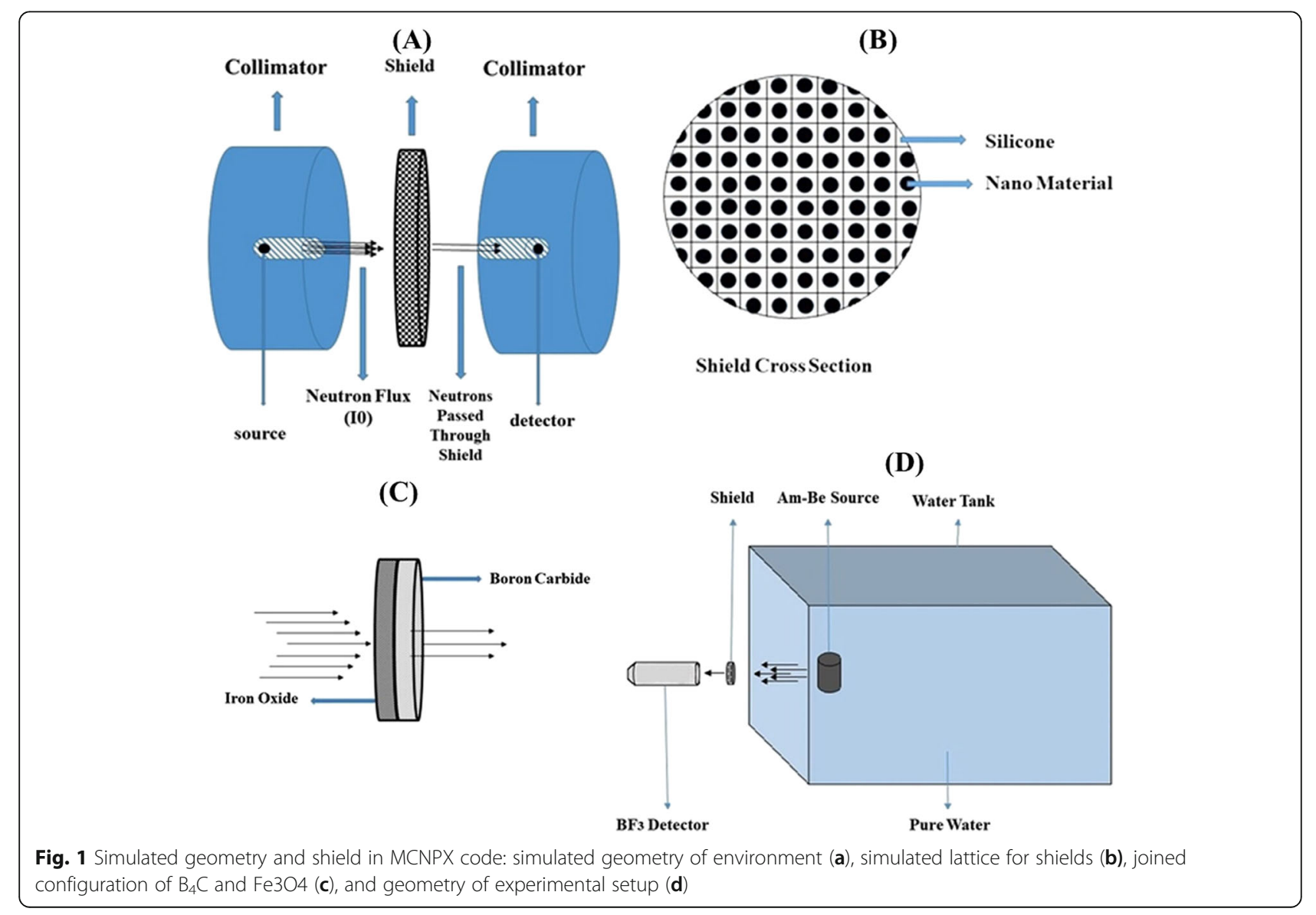


(A)

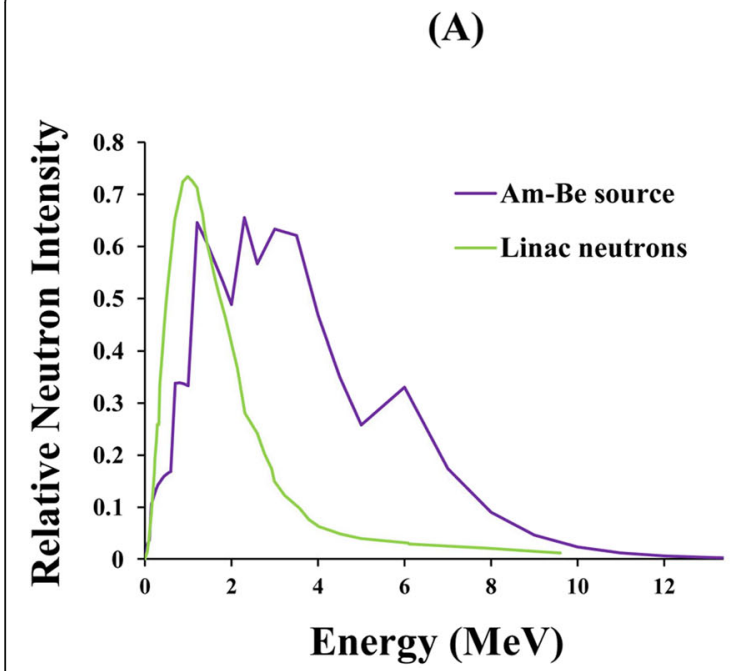

(B)

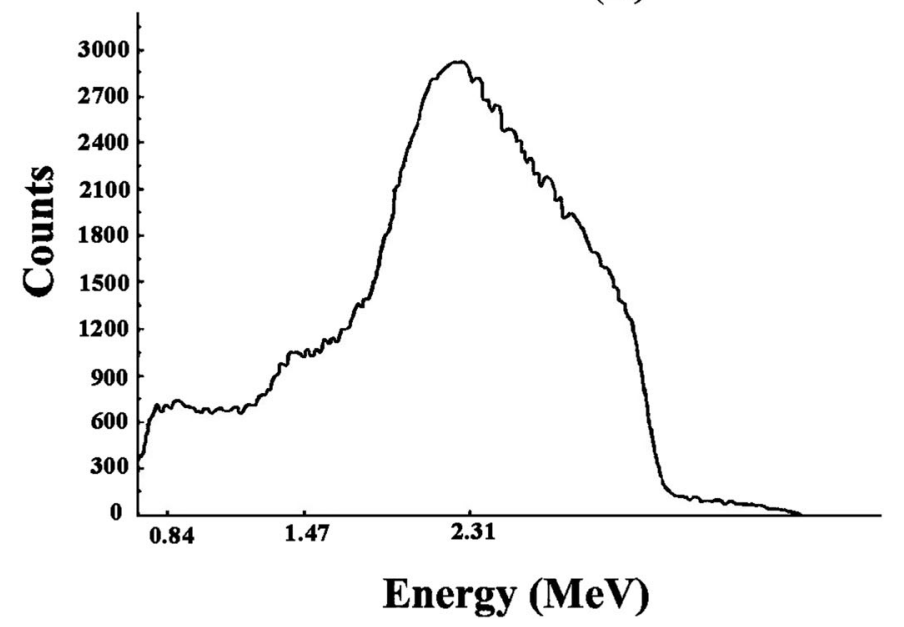

Fig. 2 Neutron energy spectra: produced in linac head and Am-Be source (a), produced in Am-Be source in the laboratory (b)

\section{Simulations validation with paraffin}

To validate the simulated model for the calculation of neutrons, the macroscopic cross-section for paraffin wax $\left(\mathrm{C}_{30} \mathrm{H}_{62}\right)$ with a density of $0.88 \mathrm{~g} / \mathrm{cm}^{3}$ and a monoenergetic neutron source $\left(\mathrm{E}\right.$ eff $\left.=4.5 \mathrm{MeV}^{241} \mathrm{Am}-\mathrm{Be}\right)$ was applied using the MC model and compared with the published reference data (34).

\section{Design of Nanoshield in MCNPX}

Nanocomposites were designed as cylinders with a diameter of $30 \mathrm{~cm}$, and the inner space was divided into cubic cells in the nanometer dimension using the lattice feature of MCNPX MC code (Fig. 1b). Nanoshields made of boron carbide and iron oxide NPs $100 \mathrm{~nm}$ in diameter in a matrix of silicone resin were simulated (Fig. 1b). These shields were modeled with a weight percentage of $10,20,30,40$, and 50 nanomaterials in silicone resin. Shields were simulated with a thickness of $0.5,1,1.5,2$, 3 , 4 , and $5 \mathrm{~cm}$ to obtain more accurate macroscopic cross-sections in different densities. Special configurations using two shields were also simulated. This simulation geometry was designed to evaluate the double-layer shielding effect of $\mathrm{Fe}_{3} \mathrm{O}_{4}$ and $\mathrm{B}_{4} \mathrm{C}$ nanoshields on photoneutrons (Fig. 1c). Two overall thicknesses of 1, 2, 3, and $4 \mathrm{~cm}$ (half thickness for each nanoshield) were simulated. Evidently, the lattice represents the silicone resin matrix of shields, and spherical NPs of $\mathrm{B}_{4} \mathrm{C}$ and $\mathrm{Fe}_{3} \mathrm{O}_{4}$. were located at the center of each cube. Depending on the nano-materials and their concentration, and considering the fixed diameter of $100 \mathrm{~nm}$ spheres of $\mathrm{B}_{4} \mathrm{C}$ and $\mathrm{Fe}_{3} \mathrm{O}_{4}$, different cube sizes were modeled to obtain different volumes and, consequently, to achieve different concentrations of each nanomaterial in each shield. Initially, nanomaterials were separately used in each shield and tested as a single-layer shield, and subsequently, nano-iron oxide and nano-boron carbide were modeled together as a double-layer shield; the iron oxide shield was placed toward the source and the boron carbide was located toward the detector.

\section{Fabrication of Nanoshields}

In the second step, nanoshields were fabricated based on the results of MC simulation. To fabricate nanoshields, nano-iron oxide and nano-boron carbide were purchased from Iranian Nanomaterials Pioneers Company and the size and homogeneity of NPs were evaluated by scanning electron micrograph (SEM). The diameter of nano-iron oxide and nano-boron carbide was equal to 20-30 nm (Fig. 3a) and $55 \mathrm{~nm}$ (Fig. 3b), respectively. Densities of silicone resin, iron oxide, and boron carbide were $1.24,5.17$, and $2.51 \mathrm{~g} / \mathrm{cm}^{3}$, respectively.

Nanoshields were prepared in cylindrical samples with a diameter of $4 \mathrm{~cm}$ and thicknesses of $0.5,1,1.5$, and 2 $\mathrm{cm}$. They were made by adding iron oxide and boron carbide to the silicone resin. Shields were separately prepared in 10, 20, and $30 \mathrm{wt} \%$ (wt.\%) of nanomaterial concentration for iron oxide and boron carbide. Four samples of nanoshields were produced for each percentage. Nano-materials were blended with silicone by an electric blender, and a hardener was added to each sample during blending. When NP concentration exceeded $30 \%$, the mixture of silicone resin and nanomaterials did not properly solidify after being mixed.

\section{Testing the Nanoshields}

Fabricated shields were tested in a laboratory with an Am-Be source (Fig. 2c). The source was placed in a water tank with the diameters of $2.5 \times 1.5 \times 1.5 \mathrm{~m}(\mathrm{~L} \times$ $\mathrm{W} \times \mathrm{H}$ ) and with $10 \mathrm{~cm}$ of pure water between source and shields (the experimental setup is illustrated in Fig. 

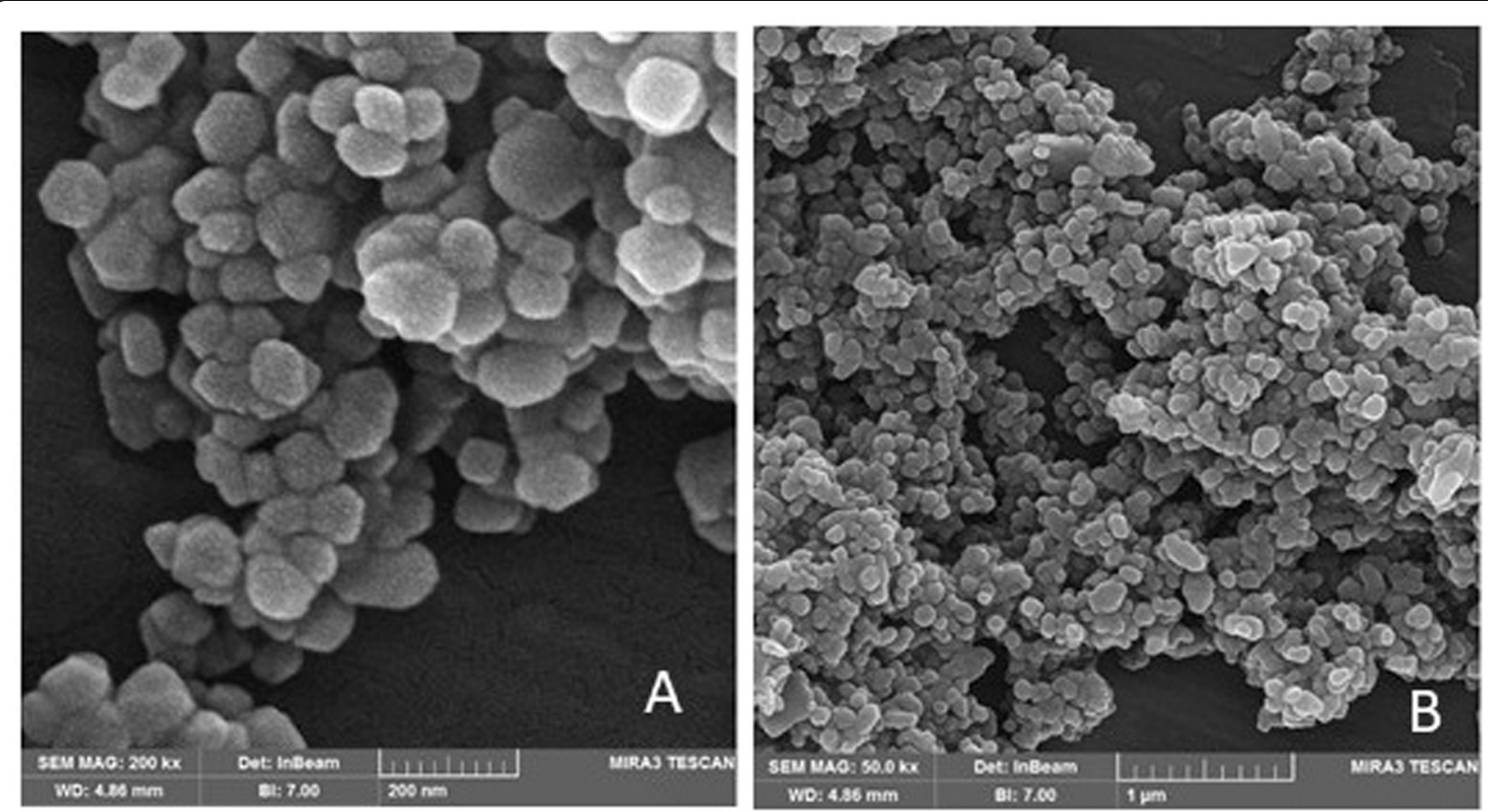

Fig. 3 Scanning electron micrograph of NPs from Iranian Nanomaterials Pioneers Company, NANOSANY; iron oxide NPs (a), boron carbide NPs (b)

1d). The $\mathrm{BF}_{3}$ neutron detector was covered with cadmium leaves to eliminate scattered neutrons. Shields were placed in front of a neutron detector with a diameter of $2 \mathrm{~cm}$.

Counts were measured in 15-min periods and repeated 3 times for each sample for averaging. The measurements were separately performed for each shield and finally done for the combined shield, including $1 \mathrm{~cm}$ of iron oxide close to the source and $1 \mathrm{~cm}$ of boron carbide toward the detector side. After the measurement, the macroscopic cross-section for iron oxide and boron carbide shields was calculated using Eq. 1.

\section{Results}

\section{Experimental measurements and MC calculations uncertainties}

The main sources of experimental uncertainties included limited accuracy of the BF3 detector, uncontrolled changes to the environment and conditions (e.g., receiving the scatted neutrons to the detector), limitations, and simplifications of the experimental procedure. In this regard, the uncertainties from the experimental setup and repeated measurements were negligible and are provided in the related sections. It is noteworthy that the statistical uncertainties of the results from the MC simulations were less than $1 \%$ in all cases.

\section{Simulations validation with lead}

The results of the simulation for the photon source and lead shield were compared with the data from the $\mathrm{Na}$ tional Institute of Standards and Technology (NIST) [33]. These results demonstrated a difference of $<1.8 \%$ with data of lead attenuation from NIST (Fig. 4).

\section{Simulations validation with paraffin}

For neutrons' source and paraffin wax, simulation results were compared with experimental data [34]. The values of the macroscopic cross-section for experimental [34] and MC methods were $0.192 \pm 0.014$ and $0.195 \mathrm{~cm}^{1}$, respectively. Considering uncertainties in neutron calculations (less than 0.01), the resulting difference of $1.5 \%$ was acceptable for our MC model validation.

\section{Macroscopic cross-section of Nanoshields for}

\section{Monoenergetic neutrons calculated by the MC method}

The macroscopic cross-sections of boron carbide and iron oxide nanocomposites were calculated for several weight percentages (wt.\%) of NPs and 10 consecutive energies. For simplicity, only the results of composites with a concentration of $50 \mathrm{wt} . \%$ are presented in Fig. 5. In general, attenuation efficiency decreases with the increase in energy, but it shows some fluctuations. In addition, attenuation efficiency is significantly higher (approximately double) for both boron carbide and iron 

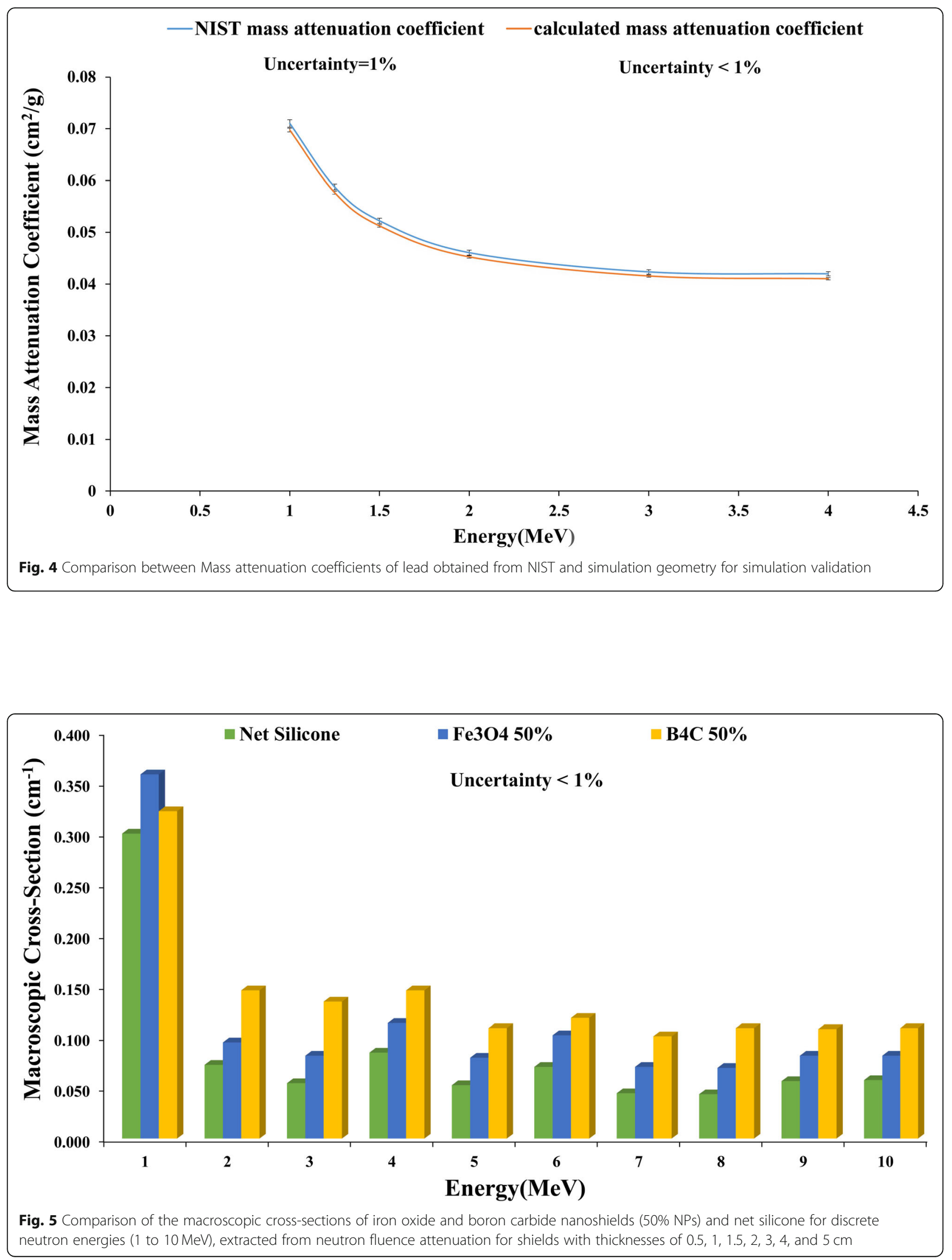
oxide at $1 \mathrm{MeV}$ compared to higher energies (2 to 10 $\mathrm{MeV})$. In all concentrations of NPs, the macroscopic cross-section was higher for boron carbide relative to iron oxide in the energy range of $2-10$, but for $1 \mathrm{MeV}$, iron oxide acted superior to boron carbide. In other words, the macroscopic cross-section of iron oxide was $\sim 11 \%$ higher than that of boron carbide in $50 \mathrm{wt} . \%$ concentration.

\section{Macroscopic cross-section of Nanoshields for neutron Spectrum of am-be source calculated by the MC method} The applied neutron spectrum (Fig. 2a) had an energy range between $0.4 \mathrm{eV}$ and $\sim 15 \mathrm{MeV}$, and mainly from 1 to $3 \mathrm{MeV}$. Transmission factors for mono- and doublelayer nanocomposites in front of the Am-Be source were calculated by the MC method (Tables 1 and 2). Based on Table $1, \mathrm{~B}_{4} \mathrm{C}$ had a superior ability in eliminating neutrons compared to $\mathrm{Fe}_{3} \mathrm{O}_{4}$ for all concentrations, and this superiority increased with filler concentration. At the concentration of $10 \mathrm{wt} . \%$, both nanocomposites showed similar attenuation, but with an increase in NP concentration, boron carbide exhibited more efficiency in eliminating neutrons. The macroscopic cross-sections of nanocomposites are depicted in Fig. 6a, which demonstrates the difference between attenuation yields of two nanocomposites. For instance, the macroscopic cross-section for boron carbide rose from $0.12 \mathrm{~cm}^{-1}$ for $10 \%$ to $0.192 \mathrm{~cm}^{-1}$ for $50 \%$. However, for iron oxide, it was $0.109 \mathrm{~cm}^{-1}$ for $10 \mathrm{wt} . \%$ and increased to $0.133 \mathrm{~cm}^{-1}$ for $50 \mathrm{wt} . \%$. Furthermore, the cross-section for the double-layer shield was equal to $0.21 \mathrm{~cm}^{-1}$ for the concentration of $50 \%$ (Fig. 6d).

The transmission factors for the concentration of $50 \%$ and a thickness of $4 \mathrm{~cm}$ were 0.59 and 0.45 for mono-layer shields of iron oxide and boron carbide, respectively, and 0.44 for the double-layer shield (Tables 1 and 2).

\section{Macroscopic cross-section of Nanoshields for neutron Spectrum of am-be source determined by experiment} The Am-Be source in the laboratory has an energy peak at $2.31 \mathrm{MeV}$ (Fig. 2c). The spectrum was provided by the company after installing the Am-Be source. Table 3 shows the experimentally measured transmission factor in different thicknesses and for various percentages of NPs. With an increase in nanomaterial concentration, boron carbide shows more efficiency in eliminating neutrons. At the percentage of 30 and a thickness of $2 \mathrm{~cm}$, it reduces the number of neutrons by $34 \%$, compared to $29 \%$ for iron oxide. As expected, attenuation for the double-layer shield is more than two nanoshields separately. The transmission factor for the double-layer shield with a thickness of $2 \mathrm{~cm}$ is 0.62 (Table 3 ).

The macroscopic cross-section in Fig. $6 \mathrm{c}$ demonstrates the difference between attenuation yields of the mentioned nanomaterials. The macroscopic cross-section for boron carbide rises by $0.04 \mathrm{~cm}^{-1}$ from 10 to $30 \%$, while this increase is $0.03 \mathrm{~cm}^{-1}$ for iron oxide.

The experimental results for monolayer shields of $\mathrm{Fe} 3 \mathrm{O} 4$ and $\mathrm{B}_{4} \mathrm{C}$ and double-layer shields (Table 3) demonstrate satisfactory agreement with the simulation results (Tables 1 and 2). The difference between $\mathrm{MC}$ and measurements is in the range of $10 \%$. There was about $9 \%$ difference between experimental measurement of neutron attenuation and $\mathrm{MC}$ results, which can be attributed to the discrepancy between fabricated nanocomposites where the NPs were heterogeneously distributed inside the resin matrix. However, in the MC simulations, NPs were homogenously dispersed with the resin matrix. Besides, the uncertainties in providing energy spectra during the installation of the AmBe neutron source as experimentally and subsequently measurements (about $5 \%$ ), primarily due to the uncertainty in the source strength, had a non-negligible effect on the observed discrepancy between MC and measurement results.

\section{Macroscopic cross-section of Nanoshields for a neutron Spectrum from Linac calculated by the MC method} The applied neutron spectrum of linac (Fig. 2a) has an energy range between $40 \mathrm{keV}$ and $\sim 10 \mathrm{MeV}$ and contains a peak at $1 \mathrm{MeV}$. Tables 1 and 2 present the attenuation in different thicknesses and for various percentages of NPs for mono- and double-layer nanoshields. As can be seen, attenuation is higher for the double-layer shield than mono-layer shields. Based on the comparison of transmission factor for mono-layer and double-layer shields (concentration of $50 \%$ and thickness of $4 \mathrm{~cm}$ ), the values for iron oxide, boron carbide, and double-layer shields were $0.53,0.40$, and 0.37 , respectively. Attenuation increases for both nanocomposites by an increase in NP concentration (wt.\%), and at $10 \mathrm{wt} . \%$, both nanocomposites show similar attenuation. However, with an increase in the weight percentage of boron carbide, it shows more efficiency in eliminating neutrons. At the percentage of 50 and a thickness of $5 \mathrm{~cm}$, it reduces the number of neutrons by $67 \%$ (Table 1 ). The reduction is only $55 \%$ for iron oxide (Table 1 ).

The macroscopic cross-section in Fig. 6b indicates the difference between attenuation yields of two nanocomposites. The macroscopic cross-section for boron carbide rose from $0.144 \mathrm{~cm}^{-1}$ for $10 \mathrm{wt} . \%$ to $0.226 \mathrm{~cm}^{-1}$ for $50 \mathrm{wt} . \%$. For iron oxide, it was $0.132 \mathrm{~cm}^{-1}$ for $10 \mathrm{wt} . \%$ and increased to $0.159 \mathrm{~cm}^{-1}$ for $50 \mathrm{wt} . \%$. According to Fig. $6 \mathrm{e}$, for double-layer shields the macroscopic cross-section increased from $0.16 \mathrm{~cm}^{-1}$ for the concentration of $10 \%$ to $0.25 \mathrm{~cm}^{-1}$ for $50 \mathrm{wt} . \%$. It is of note that for each spectra, a permanent increase is observed in attenuation as the concentration of the NPs increases (Fig. 6).

Figure $7 \mathrm{a}$ and $\mathrm{b}$ demonstrate the energy spectra of neutrons reaching the detector for a total thickness of 2 $\mathrm{cm}$ of all studied nanocomposites (50\% NPs) in front of 
Table 1 Transmission factor comparison for mono-layer nanomaterial shields for Am-Be and linac spectra simulation (Uncertainties < 0.01)

\begin{tabular}{|c|c|c|c|c|c|}
\hline Nano Material Concentration & Samples Thickness (cm) & \multicolumn{2}{|c|}{ Am-Be Spectrum $\left(1 / / I_{0}\right)$} & \multicolumn{2}{|c|}{ Linac Spectrum $\left(1 / \mathrm{I}_{0}\right)$} \\
\hline \multirow[t]{9}{*}{ Net Silicone } & 0.5 & \multicolumn{2}{|l|}{0.94} & \multicolumn{2}{|l|}{0.94} \\
\hline & 1 & \multicolumn{2}{|l|}{0.91} & \multicolumn{2}{|l|}{0.87} \\
\hline & 1.5 & \multicolumn{2}{|l|}{0.85} & \multicolumn{2}{|l|}{0.85} \\
\hline & 2 & \multicolumn{2}{|l|}{0.82} & \multicolumn{2}{|l|}{0.76} \\
\hline & 3 & \multicolumn{2}{|l|}{0.74} & \multicolumn{2}{|l|}{0.67} \\
\hline & 4 & \multicolumn{2}{|l|}{0.67} & \multicolumn{2}{|l|}{0.59} \\
\hline & 5 & \multicolumn{2}{|l|}{0.60} & \multicolumn{2}{|l|}{0.52} \\
\hline & Samples Thickness (cm) & \multicolumn{2}{|c|}{ Am-Be Spectrum $\left(1 / I_{0}\right)$} & \multicolumn{2}{|c|}{ Linac Spectrum $\left(\mathrm{I} / \mathrm{I}_{0}\right)$} \\
\hline & & $\mathrm{Fe}_{3} \mathrm{O}_{4}$ & $\mathrm{~B}_{4} \mathrm{C}$ & $\mathrm{Fe}_{3} \mathrm{O}_{4}$ & $\mathrm{~B}_{4} \mathrm{C}$ \\
\hline \multirow{7}{*}{$\begin{array}{l}10 \% \text { Wt. nano material, } \\
90 \% \text { Wt. silicone }\end{array}$} & 0.5 & 0.95 & 0.94 & 0.93 & 0.93 \\
\hline & 1 & 0.89 & 0.88 & 0.87 & 0.85 \\
\hline & 1.5 & 0.85 & 0.83 & 0.82 & 0.80 \\
\hline & 2 & 0.79 & 0.79 & 0.75 & 0.73 \\
\hline & 3 & 0.71 & 0.69 & 0.66 & 0.63 \\
\hline & 4 & 0.64 & 0.62 & 0.59 & 0.55 \\
\hline & 5 & 0.58 & 0.55 & 0.51 & 0.49 \\
\hline \multirow{7}{*}{$\begin{array}{l}20 \% \text { Wt. nano material, } \\
80 \% \text { Wt. silicone }\end{array}$} & 0.5 & 0.95 & 0.94 & 0.93 & 0.92 \\
\hline & 1 & 0.88 & 0.88 & 0.87 & 0.84 \\
\hline & 1.5 & 0.84 & 0.81 & 0.81 & 0.78 \\
\hline & 2 & 0.79 & 0.76 & 0.75 & 0.72 \\
\hline & 3 & 0.71 & 0.67 & 0.65 & 0.61 \\
\hline & 4 & 0.63 & 0.59 & 0.57 & 0.53 \\
\hline & 5 & 0.57 & 0.52 & 0.49 & 0.45 \\
\hline \multirow{7}{*}{$\begin{array}{l}30 \% \text { Wt. nano material, } \\
70 \% \text { Wt. silicone }\end{array}$} & 0.5 & 0.94 & 0.93 & 0.93 & 0.92 \\
\hline & 1 & 0.88 & 0.86 & 0.86 & 0.83 \\
\hline & 1.5 & 0.83 & 0.80 & 0.79 & 0.76 \\
\hline & 2 & 0.79 & 0.74 & 0.74 & 0.69 \\
\hline & 3 & 0.70 & 0.64 & 0.64 & 0.58 \\
\hline & 4 & 0.62 & 0.55 & 0.55 & 0.48 \\
\hline & 5 & 0.55 & 0.48 & 0.49 & 0.40 \\
\hline \multirow{7}{*}{$\begin{array}{l}40 \% \text { Wt. nano material, } \\
60 \% \text { Wt. silicone }\end{array}$} & 0.5 & 0.94 & 0.92 & 0.93 & 0.90 \\
\hline & 1 & 0.87 & 0.84 & 0.85 & 0.81 \\
\hline & 1.5 & 0.82 & 0.77 & 0.79 & 0.73 \\
\hline & 2 & 0.77 & 0.71 & 0.73 & 0.66 \\
\hline & 3 & 0.68 & 0.60 & 0.63 & 0.54 \\
\hline & 4 & 0.60 & 0.50 & 0.54 & 0.44 \\
\hline & 5 & 0.53 & 0.43 & 0.47 & 0.36 \\
\hline \multirow{7}{*}{$\begin{array}{l}50 \% \text { Wt. nano material, } \\
50 \% \text { Wt. silicone }\end{array}$} & 0.5 & 0.94 & 0.91 & 0.93 & 0.89 \\
\hline & 1 & 0.87 & 0.82 & 0.84 & 0.79 \\
\hline & 1.5 & 0.81 & 0.75 & 0.77 & 0.71 \\
\hline & 2 & 0.76 & 0.68 & 0.72 & 0.63 \\
\hline & 3 & 0.67 & 0.57 & 0.62 & 0.51 \\
\hline & 4 & 0.59 & 0.45 & 0.53 & 0.40 \\
\hline & 5 & 0.51 & 0.39 & 0.45 & 0.33 \\
\hline
\end{tabular}


Table 2 Transmission factor comparison for double-layer nanoshields for Am-Be source and linac spectra simulation (Uncertainties < 0.01 )

\begin{tabular}{|c|c|c|c|}
\hline Nano Material Concentration & Samples thickness $(\mathrm{cm})$ & Am-Be Spectrum $\left(1 / I_{0}\right)$ & Linac Spectrum $\left(\mathrm{I} / \mathrm{I}_{0}\right)$ \\
\hline \multirow[t]{4}{*}{ Net silicone } & 1 & 0.91 & 0.87 \\
\hline & 2 & 0.82 & 0.76 \\
\hline & 3 & 0.74 & 0.67 \\
\hline & 4 & 0.67 & 0.59 \\
\hline \multirow[t]{4}{*}{$10 \%$ Wt. nano material, $90 \% W t$. silicone } & 1 & 0.88 & 0.85 \\
\hline & 2 & 0.77 & 0.73 \\
\hline & 3 & 0.68 & 0.62 \\
\hline & 4 & 0.59 & 0.54 \\
\hline \multirow[t]{4}{*}{$20 \%$ Wt. nano material, $80 \% W t$. silicone } & 1 & 0.86 & 0.84 \\
\hline & 2 & 0.76 & 0.71 \\
\hline & 3 & 0.65 & 0.60 \\
\hline & 4 & 0.56 & 0.51 \\
\hline \multirow[t]{4}{*}{$30 \%$ Wt. nano material, $70 \% W t$. silicone } & 1 & 0.84 & 0.83 \\
\hline & 2 & 0.73 & 0.67 \\
\hline & 3 & 0.61 & 0.55 \\
\hline & 4 & 0.50 & 0.46 \\
\hline \multirow[t]{4}{*}{$40 \%$ Wt. nano material, $60 \% \mathrm{Wt}$. silicone } & 1 & 0.83 & 0.80 \\
\hline & 2 & 0.70 & 0.63 \\
\hline & 3 & 0.58 & 0.52 \\
\hline & 4 & 0.45 & 0.43 \\
\hline \multirow[t]{4}{*}{$50 \%$ Wt. nano material, $50 \%$ Wt. silicone } & 1 & 0.81 & 0.77 \\
\hline & 2 & 0.67 & 0.60 \\
\hline & 3 & 0.55 & 0.49 \\
\hline & 4 & 0.44 & 0.37 \\
\hline
\end{tabular}

the Am-Be and linac spectra, respectively. These nanocomposites include $2 \mathrm{~cm}$ of iron oxide, boron carbide, and $2 \mathrm{~cm}$ of double-layer shields $(1 \mathrm{~cm}$ for iron oxide and $1 \mathrm{~cm}$ for boron carbide).

\section{Discussion}

Studies have shown the production of neutrons during radiation therapy with high-energy photons $(\mathrm{E}>10 \mathrm{MV})$ $[2,3,35]$. To eliminate these neutrons, shields such as concrete, $\mathrm{B}_{4} \mathrm{C}$, and other materials have been designed to efficiently remove thermal neutrons $[6,21,36]$. Other materials such as $\mathrm{Fe}_{3} \mathrm{O}_{4}$ are utilized for shielding fast neutrons $[17,26]$. Recent investigations have reported the advantage and higher efficiency of composite shields with fine and nano-sized particles over larger or microsized particles as neutron shields [21-23]. In this study, silicone resin was chosen as the shield matrix because of its better flexibility, biocompatibility, and durability against humidity and physical damage [37]. Considering the macroscopic cross-section of net silicone resin in all simulation surveys, because of its low atomic weight (which increases the probability of elastic interaction between neutron and nucleus), it shows acceptable neutron attenuation and can be considered as an effective part of the shield. In the present research, neutron attenuation was assessed in silicone resin loaded with different concentrations of nano-sized boron carbide and iron oxide in three simulated spectra and one experimental spectrum of Am-Be source.

In the $\mathrm{MC}$ simulation, monoenergetic neutrons were applied during the calculations to provide more information concerning the attenuation efficiencies of samples for different neutron energies. A comparison of both types of nanoshields showed that neither had complete superiority over the other in the entire range of neutron energies (Table 1). Examination of the attenuation in each monoenergetic neutron source revealed that each nanocomposite had its own merits in specific neutron energy (Fig. 5). It can be claimed that both $\mathrm{Fe}_{3} \mathrm{O}_{4}$ and $\mathrm{B}_{4} \mathrm{C}$ have the highest neutron attenuation in $1 \mathrm{MeV}$ energy (Fig. 5), which corresponds to the peak of the linac energy spectrum (Fig. 2a). Moreover, the previous simulation and experimental results indicated that the contribution of thermal neutrons on the neutron spectra from the modern linacs is slight and about $6 \%[38,39]$. Thus, a shield consisting of $\mathrm{Fe}_{3} \mathrm{O}_{4}$ and $\mathrm{B}_{4} \mathrm{C}$ can be more 


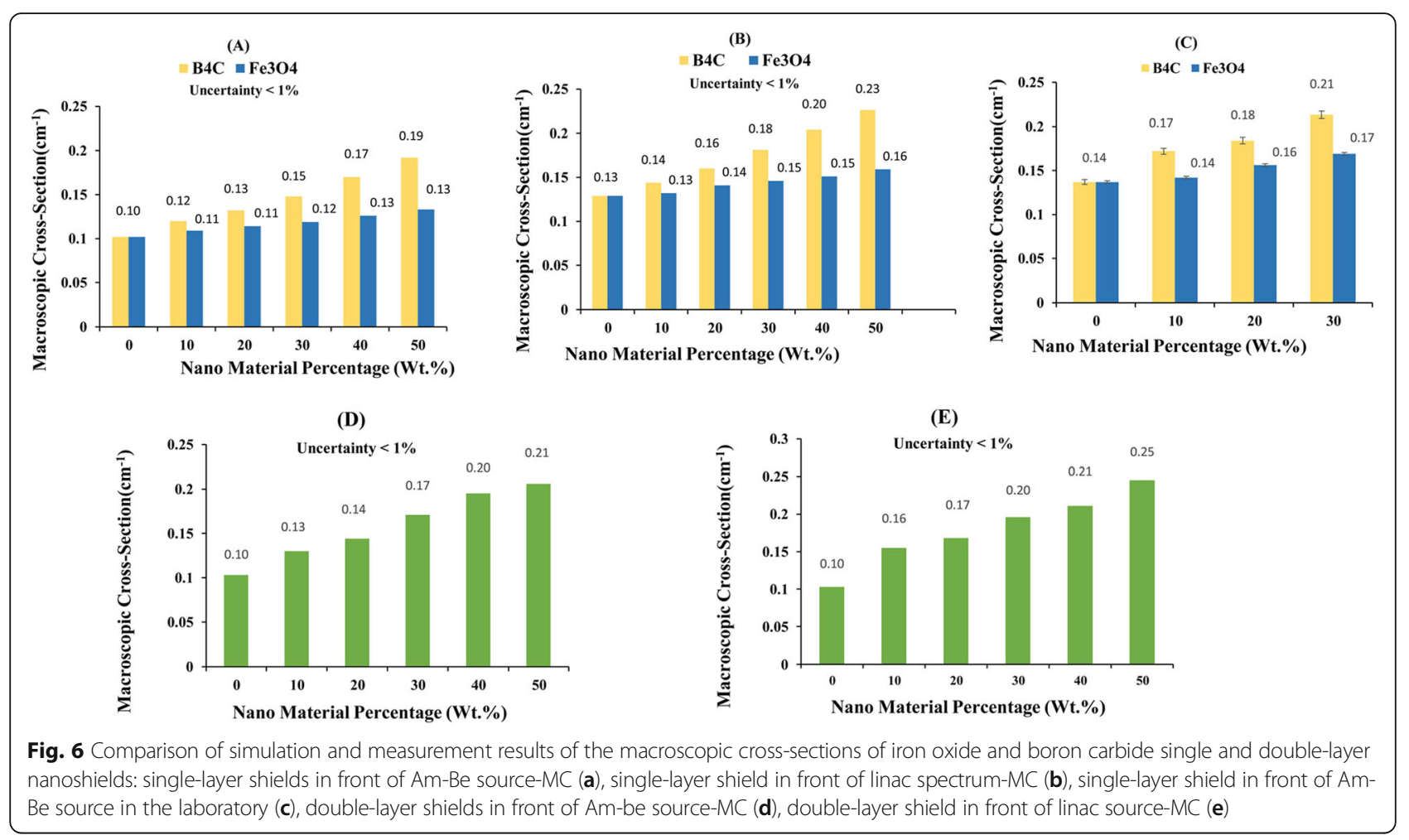

Table 3 Transmission factor comparison for experimental nanoshields with Am-Be source

\begin{tabular}{|c|c|c|c|}
\hline Nano Material Concentration & Samples thickness (cm) & Net silicone $\left(I / I_{0}\right)$ & \\
\hline \multirow[t]{5}{*}{ Net silicone } & 0.5 & $0.96 \pm 0.002$ & \\
\hline & 1 & $0.90 \pm 0.003$ & \\
\hline & 1.5 & $0.84 \pm 0.005$ & \\
\hline & 2 & $0.76 \pm 0.009$ & \\
\hline & Samples thickness $(\mathrm{cm})$ & $\mathrm{Fe}_{3} \mathrm{O}_{4}\left(\mathrm{I} / \mathrm{I}_{0}\right)$ & $\mathrm{B}_{4} \mathrm{C}\left(\mathrm{I} / \mathrm{I}_{0}\right)$ \\
\hline \multirow[t]{4}{*}{$10 \%$ Wt. nano material, $90 \% \mathrm{Wt}$. silicone } & 0.5 & $0.95 \pm 0.002$ & $0.95 \pm 0.003$ \\
\hline & 1 & $0.89 \pm 0.002$ & $0.86 \pm 0.01$ \\
\hline & 1.5 & $0.82 \pm 0.006$ & $0.79 \pm 0.01$ \\
\hline & 2 & $0.75 \pm 0.007$ & $0.71 \pm 0.007$ \\
\hline \multirow[t]{4}{*}{$20 \%$ Wt. nano material, $80 \%$ Wt. silicone } & 0.5 & $0.95 \pm 0.002$ & $0.92 \pm 0.007$ \\
\hline & 1 & $0.87 \pm 0.007$ & $0.83 \pm 0.005$ \\
\hline & 1.5 & $0.80 \pm 0.009$ & $0.75 \pm 0.001$ \\
\hline & 2 & $0.74 \pm 0.003$ & $0.70 \pm 0.01$ \\
\hline \multirow[t]{4}{*}{$30 \%$ Wt. nano material, $70 \% \mathrm{Wt}$. silicone } & 0.5 & $0.92 \pm 0.006$ & $0.89 \pm 0.006$ \\
\hline & 1 & $0.85 \pm 0.01$ & $0.79 \pm 0.005$ \\
\hline & 1.5 & $0.78 \pm 0.003$ & $0.70 \pm 0.004$ \\
\hline & 2 & $0.71 \pm 0.01$ & $0.66 \pm 0.02$ \\
\hline Double layer $\left(\mathrm{Fe}_{3} \mathrm{O}_{4}\right.$ and $\left.\mathrm{B}_{4} \mathrm{C}\right)$ & 2 & $\mathrm{I} / \mathrm{I}_{0}=0.62 \pm 0.01$ & \\
\hline
\end{tabular}




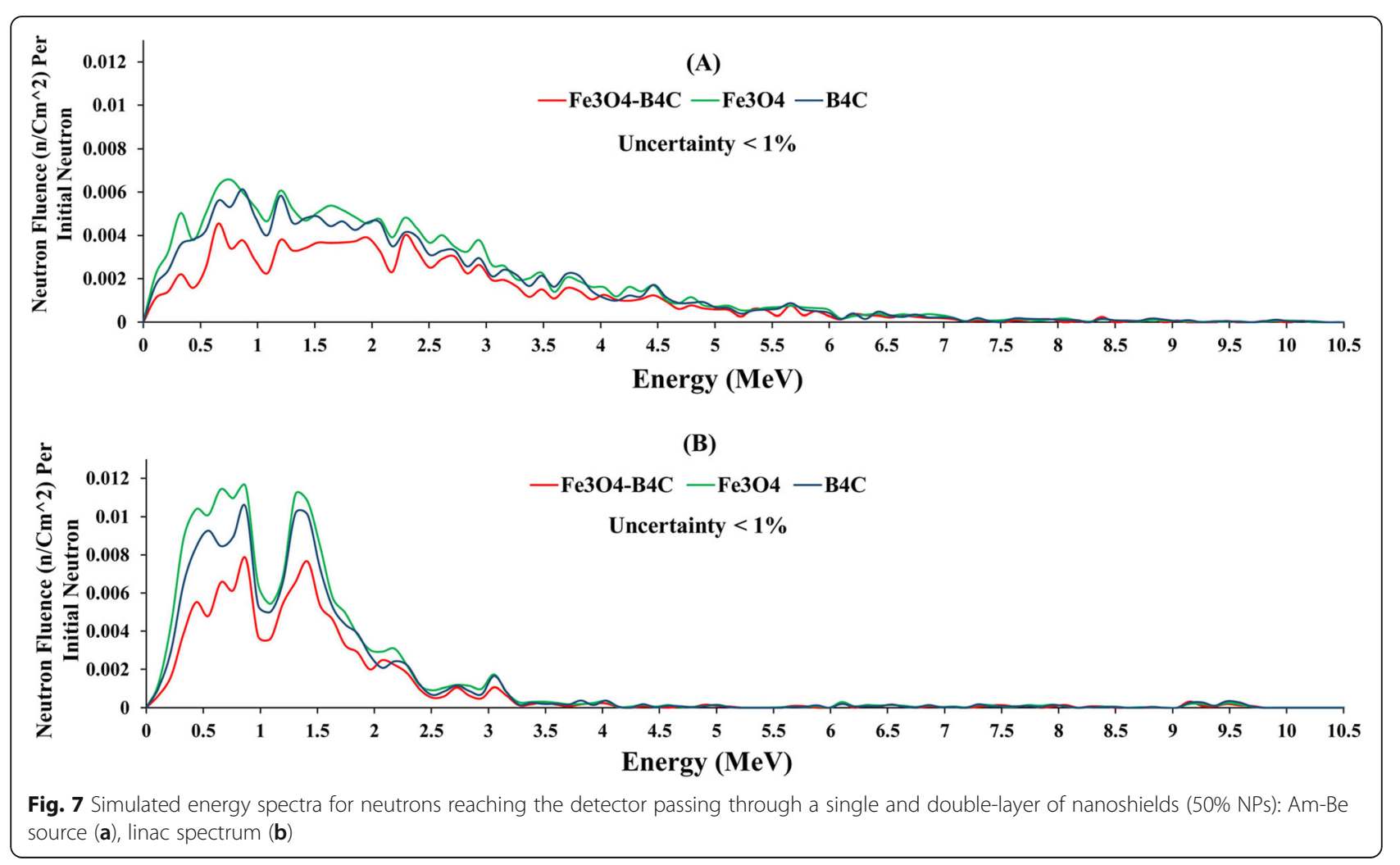

effective in shielding patients against neutrons produced by linac head during radiotherapy.

For MC simulation (Am-Be and linac spectra) and measurement with Am-Be source, both shields demonstrated acceptable efficiency in attenuating neutrons, but boron carbide was superior in eliminating neutrons compared with iron oxide (Fig. 6a, b, and c and Table 1). As expected, the simulated double-layer shield exhibited greater macroscopic cross-section relative to both monolayer $\mathrm{Fe}_{3} \mathrm{O}_{4}$ and $\mathrm{B}_{4} \mathrm{C}$ nanocomposites (Figs. $6 \mathrm{~d}$ and e; Tables 1 and 2). The efficiency of nanocomposites in eliminating neutrons from the linac spectrum was similar to the results of the Am-Be spectrum in the MC simulations. Nevertheless, it showed a slightly higher neutron macroscopic cross-section (Figs. 6d and e; Tables 1 and 2), which can be attributed to the lower neutron energy of the linac spectrum. Besides, the discrepancy between two nanocomposites in terms of the macroscopic cross-section was higher for the linac spectrum (Fig. 6b). Similar to other neutron spectra studied in our investigation, the double-layer shield showed a larger macroscopic cross-section compared to other monolayer nanocomposites (Tables 1 and 2).

It can be deducted from Fig. 7a (detected spectra) that neutron energy spectra of Am-Be source have attenuated and shifted to lower energies relative to initial spectra (Fig. 2a) and minimum attenuation occurred in energy regions between $0.5-1 \mathrm{MeV}$ for both nano materials. Moreover, at the energy of less than $3 \mathrm{MeV}$, boron carbide acts better than iron oxide. The neutron energy spectra from the linac source (Fig. 7b) also declined but with fluctuations without any shifting to lower energies relative to initial spectra (Fig. 2a). The maximum reduction occurred at the energy peak of initial spectra $(\sim 1$ $\mathrm{MeV}$ ) for both nano materials. In addition, in lower energy regions, boron carbide acts better than iron oxide, but the double-layer shield has the highest attenuation for both sources.

In the current study, the weights of experimentally made shields with thickness and radius of $2 \mathrm{~cm}$ for net silicone, iron oxide (50\% concentration), and boron carbide (50\% concentration) were 31,60 , and $41 \mathrm{~g}$, respectively, and for the double-layer shield, it was $50.5 \mathrm{~g}$. It should be noted that the matrix of silicone resin produces an additional shielding for neutrons due to its low atomic weight. In addition, its mechanical properties make the shield suitable for application as a flexible sheet on the patient. According to our calculations and considering the weight of the nanocomposite, a double-layer nanocomposite can be used as a flexible and light shield on the patient body. For instance, a 2 -cm-thick double-layer nanocomposite (50\% concentration) will result in a $40 \%$ reduction in the patient's received neutron fluence during radiation therapy with the $18 \mathrm{MeV}$ photon beam (Table 2). It is of note that the reduction in the neutron fluence increases with nanoshield thickness and concentration of NPs so that a double-layer of nanocomposite with $4 \mathrm{~cm}$ in thickness and $50 \%$ concentration 
can reduce the neutron fluence for $18 \mathrm{MeV}$ photon beam of the linac by $63 \%$ (Table 2).

Several studies have been conducted to evaluate the neutron cross-section of different materials and compounds. For instance, D'Mellow et al. and Soltani et al. reported a high efficiency of boron carbide in removing thermal neutrons [21, 36]. Also, El-Khayatt et al. and Tellili et al. assessed different materials for shielding fast neutrons. Among these materials, iron oxide has an acceptable crosssection against fast neutrons [40, 41]. Nevertheless, before the present study, there was no study on the combined effect of double-layer nanocomposites in eliminating photoneutrons from the linac. In this context, evaluating the other nanoshields to eliminate thermal and fast neutrons simultaneously from sources with many thermal and fast neutrons may be a topic for future investigations.

\section{Conclusion}

According to the results of this study, iron oxide-doped nanocomposite acted better in eliminating and attenuating fast neutrons, mostly around $1 \mathrm{MeV}$ relative to boron carbide-doped nanocomposite. Our designed double-layer nanocomposite showed greater efficiency in eliminating fast neutrons. The results of MC simulations and the experimental test thoroughly comply with the mentioned statement. Considering the low weight and flexibility of the designed double-layer nanocomposite, it can be efficiently applied for protecting patients against neutrons produced from the linac head during radiation therapy with the $18 \mathrm{MeV}$ photon beam.

\section{Abbreviations}

Linac: Medical linear accelerator; NPs: Nanoparticles; MC: Monte Carlo; RBE: Relative biological effectiveness; SEM: Scanning electron micrograph; NIST: National institute of standards and technology

\section{Acknowledgements}

We are especially thankful from Vice Chancellor for Research (VCR) of Urmia University of Medical Sciences, who approved and supported this project.

\section{Authors' contributions}

$\mathrm{NJ}, \mathrm{AM}$ and $Y A$ were responsible for the conceptualization and acquisition of the data. NJ, AM YA, AA, and FZ were responsible for the methodology. NJ, $A M Y A, A A$, and $F Z$ were responsible for the writing, review, and/or revision of the manuscript. NJ, AM YA, AA, and FZ were responsible for the administrative, technical, or material support. $\mathrm{NJ}$ and $\mathrm{AM}$ were responsible for the study supervision. All authors read and approved the final manuscript.

\section{Funding}

The current work was supported by a grant number: IR.UMSU.REC. 1397.235.

\section{Availability of data and materials}

The dataset used and analyzed during the current study are available from the corresponding author on reasonable request.

\section{Ethics approval and consent to participate}

The ethics committee of Urmia University of Medical Sciences approved the all procedures of this experiment (ethical approval no:

IR.UMSU.REC.1397.235).
Consent for publication

All authors have given consent for publication.

\section{Competing interests}

The authors declare that they have no conflicts of interest.

\section{Author details}

${ }^{1}$ Department of Medical Physics, Faculty of Medicine, Urmia University of Medical Sciences, Urmia, Iran. ${ }^{2}$ Molecular Medicine Research Center, Tabriz University of Medical Sciences, Tabriz, Iran. ${ }^{3}$ Department of Inorganic

Chemistry, Faculty of chemistry, Tabriz University, Tabriz, Iran. ${ }^{4}$ Department of Physics, Faculty of Basic Sciences, University Of Mohaghegh Ardebili, Ardabil, Iran. ${ }^{5}$ Solid Tumor Research Center, Cellular and Molecular Medicine Institute, Urmia University of Medical Sciences, Urmia, Iran.

Received: 31 October 2019 Accepted: 27 April 2020

Published online: 11 May 2020

\section{References}

1. Mesbahi A, Azarpeyvand A-A, Shirazi A. Photoneutron production and backscattering in high density concretes used for radiation therapy shielding. Ann Nucl Energy. 2011;38(12):2752-6.

2. Naseri A, Mesbahi A. A review on photoneutrons characteristics in radiation therapy with high-energy photon beams. Rep Pract Oncol Radiother. 2010; 15(5):138-44.

3. Vega-Carrillo HR, Baltazar-Raigosa A. Photoneutron spectra around an $18 \mathrm{MV}$ LINAC. J Radioanal Nucl Chem. 2010;287(1):323-7.

4. Jumpee $C$, Wongsawaeng $D$. Innovative neutron shielding materials composed of natural rubber-styrene butadiene rubber blends, boron oxide and iron(III) oxide. J Phys Conf Ser. 2015;611:012019.

5. Kiani MA, Ahmadi SJ, Outokesh M, Adeli R, Mohammadi A. Preparation and characteristics of epoxy/clay/B ${ }_{4} C$ nanocomposite at high concentration of boron carbide for neutron shielding application. Radiat Phys Chem. 2017; 141:223-8.

6. Kim J, Lee B-C, Uhm YR, Miller WH. Enhancement of thermal neutron attenuation of nano- $\mathrm{B}_{4} \mathrm{C}$, $-\mathrm{BN}$ dispersed neutron shielding polymer nanocomposites. J Nucl Mater. 2014;453(1-3):48-53.

7. Kaur U, Sharma JK, Singh PS, Singh T. Comparative studies of different concretes on the basis of some photon interaction parameters. Appl Radiat Isot. 2012;70(1):233-40.

8. Kry SF, Bednarz B, Howell RM, Dauer L, Followill D, Klein E, et al. Measurement and calculation of doses outside the treated volume from external-beam radiation therapy. Med Phys. 2017:44(10):e391-429.

9. Barquero R, Edwards TM, Iniguez MP, Vega-Carrillo HR. Monte Carlo simulation estimates of neutron doses to critical organs of a patient undergoing 18 MV x-ray LINAC-based radiotherapy. Med Phys. 2005;32(12): 3579-88.

10. Mesbahi A, Seyednejad F, Gasemi-Jangjoo A. Estimation of organs doses and radiation-induced secondary cancer risk from scattered photons for conventional radiation therapy of nasopharynx: a Monte Carlo study. Jpn J Radiol. 2010;28(5):398-403.

11. Mohammadzadeh M, Mesbahi A. MC estimation of out-of-field organ doses from scattered photons, photoneutrons, and capture gamma rays in prostate radiation therapy. Nucl Technol Radiat Prot. 2010;25(2):78-84.

12. Kliauga $\mathrm{P}, \mathrm{Amols} \mathrm{H}$. Photoneutrons from high energy medical linear accelerators: measurement of the spectrum and dose using a miniature proportional counter. Int J Radiat Oncol Biol Phys. 1995;31(3):629-33.

13. Allen PD, Chaudhri M. Photoneutron production in tissue during high energy bremsstrahlung radiotherapy. Phys Med Biol. 1988;33(9):1017.

14. Guo S, Ziemer PL. Health physics aspects of neutron activated components in a linear accelerator. Health Phys. 2004:86:S94-S102.

15. Hälg RA, Besserer J, Boschung M, Mayer S, Lomax AJ, Schneider U. Measurements of the neutron dose equivalent for various radiation qualities, treatment machines and delivery techniques in radiation therapy. Phys Med Biol. 2014;59(10):2457-68.

16. Mortazavi SMJ, Kardan M, Sina S, Baharvand H, Sharafi N. Design and fabrication of high density borated polyethylene nanocomposites as a neutron shield. Int J Radiat Rese. 2016;14(4):379-83.

17. Sallam HA, Saudy HA. The role of replacing CdO by Fe2O3 on the fast neutron removal cross sections in cd-Boro phosphate glass shield. World J Condens Matter Phy. 2013;3:62-6. 
18. Zhou D, Zhang Q-P, Zheng J, Wu Y, Zhao Y, Zhou Y-L. Co-shielding of neutron and $\gamma$-ray with bismuth borate nanoparticles fabricated via a facile sol-gel method. Inorg Chem Commun. 2017;77:55-8.

19. Kipcak AS, Gurses P, Derun EM, Tugrul N, Piskin S. Characterization of boron carbide particles and its shielding behavior against neutron radiation. Energy Convers Manag. 2013;72:39-44.

20. Rudd PJ, Prior D, Austin-Smith S. Neutron contamination of $10 \mathrm{MV} \mathrm{X-rays:} \mathrm{its}$ relevance to treatment room door and maze design. Br J Radiol. 2007; 80(954):469-75.

21. Soltani Z, Beigzadeh A, Ziaie F, Asadi E. Effect of particle size and percentages of boron carbide on the thermal neutron radiation shielding properties of $\mathrm{HDPE} / \mathrm{B}_{4} \mathrm{C}$ composite: experimental and simulation studies. Radiat Phys Chem. 2016;127:182-7.

22. Tekin HO, Singh VP, Manici T. Effects of micro-sized and nano-sized WO 3 on mass attenauation coefficients of concrete by using MCNPX code. Appl Radiat Isot. 2017;121:122-5.

23. Künzel $R$, Okuno E. Effects of the particle sizes and concentrations on the Xray absorption by CuO compounds. Appl Radiat Isot. 2012;70(4):781-4.

24. Abdullah Y, Ariffin FNT, Hamid R, Yusof MR, Zali NM, Ahmad MHARM, et al. Preliminary study of neutron absorption by concrete with boron carbide addition 2014:101-104.

25. Akkas A, Tugrul AB, Buyuk B, Addemir AO, Marsoglu M, Agacan B. Shielding effect of boron carbide aluminium metal matrix composite against gamma and neutron radiation. Acta Physica Polonica A. 2015, 128;(2B):B-176-B-80.

26. Saudi HA, Mostafa AG, Sheta N, El Kameesy SU, Sallam HA. The structural properties of $\mathrm{CdO}-\mathrm{Bi} 2 \mathrm{O} 3$ borophosphate glass system containing Fe2O3 and its role in attenuating neutrons and gamma rays. Phys B Condens Matter. 2011:406(21):4001-6.

27. McAlister DR. Neutron shielding materials. 2016.

28. Team X-MC. MCNP — a General Monte Carlo N-particle transport code, version 5. 2008

29. Guarrini FD, Malaroda R. Two different technique measurements of the neutron spectrum of an am-be source. Nucl Inst Methods. 1971;92(2): $277-84$

30. Vijaya AD, Kumar A. The neutron spectrum of am-be neutron sources. Nucl Inst Methods. 1973;111(3):435-40

31. Facure A, Falcao RC, Silva AX, Crispim VR, Vitorelli JC. A study of neutron spectra from medical linear accelerators. Appl Radiat Isot. 2005;62(1):69-72.

32. Kralik M, Turek K, Vondracek V. Spectra of photoneutrons produced by highenergy X-ray radiotherapy linacs. Radiat Prot Dosim. 2008;132(1):13-7.

33. Hubbell JH, Seltzer SM. Tables of $X$-ray mass attenuation coefficients and mass energy-absorption coefficients $1 \mathrm{keV}$ to $20 \mathrm{MeV}$ for elements $Z=1$ to 92 and 48 additional substances of dosimetric interest. National Inst. of Standards and Technology-PL, Gaithersburg, MD (United ...; 1995.

34. Korkut $T$, Karabulut A, Budak G, Korkut H. Investigation of fast neutron shielding characteristics depending on boron percentages of MgB2, $\mathrm{NaBH} 4$ and KBH4. J Radioanal Nucl Chem. 2010;286(1):61-5.

35. Ongaro C, Zanini A, Nastasi U, Ródenas J, Ottaviano G, Manfredotti C, et al. Analysis of photoneutron spectra produced in medical accelerators. Phys Med Biol. 2000:45(12):L55-61.

36. D'Mellow B, Thomas DJ, Joyce MJ, Kolkowski P, Roberts NJ, Monk SD. The replacement of cadmium as a thermal neutron filter. Nucl Instrum Methods Phys Res Sect A: Accelerators, Spectrometers, Detectors Assoc Equip. 2007; 577(3):690-5.

37. Elmahroug $Y$, Tellili B, Souga C. Determination of shielding parameters for different types of resins. Ann Nucl Energy. 2014;63:619-23.

38. Howell RM, Kry SF, Burgett E, Hertel NE, Followill DS. Secondary neutron spectra from modern Varian, Siemens, and Elekta linacs with multileaf collimators. Med Phys. 2009;36(9):4027-38

39. Kase KR, Mao XS, Nelson WR, Liu JC, Kleck JH, Elsalim M. Neutron fluence and energy spectra around the Varian Clinac 2100C/2300C medical accelerator. Health Phys. 1998;74(1):38-47.

40. El-Khayatt AM. Calculation of fast neutron removal cross-sections for some compounds and materials. Ann Nucl Energy. 2010;37(2):218-22.

41. Tellili B, Elmahroug Y, Souga C. Calculation of fast neutron removal cross sections for different lunar soils. Adv Space Res. 2014:53(2):348-52.

\section{Publisher's Note}

Springer Nature remains neutral with regard to jurisdictional claims in published maps and institutional affiliations.

\section{Ready to submit your research? Choose BMC and benefit from:}

- fast, convenient online submission

- thorough peer review by experienced researchers in your field

- rapid publication on acceptance

- support for research data, including large and complex data types

- gold Open Access which fosters wider collaboration and increased citations

- maximum visibility for your research: over $100 \mathrm{M}$ website views per year

At $\mathrm{BMC}$, research is always in progress.

Learn more biomedcentral.com/submissions 